\title{
Difference between Metaphysics and Physical Applications; Comparison of Classical and New Patient Positioning
}

\author{
Hiroko Tadaura ${ }^{1^{*}}$ \\ ${ }^{1}$ Graduate School of Health and Welfare, International University of Health and Welfare, Tokyo, Japan \\ Received Date: December 15, 2020 Accepted Date: January 02, 2021 Published Date: March 30, 2021 \\ Citation: Hiroko Tadaura(2021). Difference between Metaphysics and Physical Applications; Comparison of Classical \\ and New Patient Positioning. POJ NursPrac Res. 5(1):1-5.DOI: https://doi.org/10.32648/2577-9516/5/1/2.
}

*Corresponding Author: Prof. Hiroko Tadaura, PhD, Graduate School of Health and Welfare, International University of Health and Welfare, 4-1-26 Akasaka, Minato-ku, Tokyo, 107-8402, Japan; Email: hiroko@tadaura.com.

\begin{abstract}
Background: The linkage between metaphysics and applied physics is the key to creation. Realization of theories and concepts applied to nursing practice into technology is a theme in any age. This study compares the classical and new Patient Positioning in Nursing skills, which is clarified in the study comparing nursing textbooks worldwide in main countries and clarifies the difference of the academic concept metaphysically.

Methods: Design analysis charts were used by the researcher and analyzed until theoretical saturation based on textbooks, papers, and expert opinions. Differences are drawn using figures of abstraction and realization.

Results: The classical technique was an ergonomic technique considering the convenience of the nurse with the purpose concept of prevention for pressure ulcers and physical transfer. The new technology focuses that patients move by themselves, and the nursing side was only the assistant role. The technology with the purpose concept realized the support of physical, mental, and social aspects.

Conclusion: Traditional Patient Positioning's are skills with two concepts and patterns, and new ones are individual and comprehensive creations with different concepts. The working energy $(\mathrm{J})$ in changing positions has been traditionally provided by nurses or Transfer Devices, not patients, but the new practice is performed by patients themselves, and nurses are the supporters of the process.
\end{abstract}

KEYWORDS: Innovation,Design, Abstraction, Concreteness, Metaphysics

\section{INTRODUCTION}

Various nursing theories and nursing concepts have been introduced classically and are used in education and practice. On the other hand, divergences and limitations between theory and practice have been reported because classical theories and concepts have a gap with modern clinical practice. Theories and concepts appropriate to the times and culture and climate of the country are required. Besides, there have been reports of growing needs for new technologies, new experiences, and new manufacturing that embody theories and concepts. Updated evidence is also required for the maintenance traditions. This study focused on the Nursing skill of Patient Positioning which is most frequently used in clinical nursing. There are classical and new technologies that are polarized globally, as revealed by the analysis of nursing textbooks in several previous research countries. This study analyzes the difference in the academic concept behind each technology and clarifies the metaphysical and physical application difference in the technology.

\section{METHODS}

The textbook of nursing theory introduces the arrangement of theory and technology, as shown in Figure 1 [1]. Design Engineering introduces Figure 2 as the creation process [2]. Referring to these image diagrams, the researcher compiled the textbooks, technical books, and experts' opinions by analyzing sentences, videos, and photos, verified the validity repeatedly until theoretical saturation was reached, and summarized the differences between concepts and the technology features in Figure 3. Seven researchers also performed validation of the data analysis.

The Metaparadigm is a conceptual framework for systematizing a specialty. The meta-paradigm of nursing science consists of 4 core concepts: "human being", "Environment", "Health", and "nursing" [3]. A concept is defined as an abstract idea or principal or a general concept that occurs in the mind, speech, thought about a particular subject [4]. Nursing theory is defined as "the creative and rigorous structuring of ideas that project temporary

Copyright: (C2021. Hiroko Tadaura. This is an open-access article distributed under the terms of the Creative Commons Attribution License, which permits unrestricted use, distribution, and reproduction in any medium, provided the original author and source are credited. 
and deliberate and systematic views of phenomena [5]. Through systematic questioning, nurses can develop knowledge related to improved patient care in nursing research or practice. Theoretically, a coherent group of general propositions were used as the principle of explanation [6]. Empirical is based on what is experienced or seen rather than on theory [7]. Metaparadigm has high abstraction than the Empirical indicator (Figure 1).

Figure 2 shows the image that a phenomenon consists of a number of concepts and empirical elements and that different phenomena can be created by reintegrating the elements or by changing the elements. This idea is used in design engineering. The etymology of the word 'design' is from the Latin word designare, which means "mark out, point out; devise; choose, designate, appoint," from de "out" (see de-) + signare "to mark," from signum "identifying mark, sign" (Figure 2) [8]. Figure 3 is a model schematically illustrating the concept, idea, purpose, intention, aim, and the feature of the technique from Figure 1 and 2, and the phenomenon to be experienced, which are constructed in one phenomenon of the Patient Positioning.

The researcher compared the description pages on Patient Positioning and mobility support in four basic nursing textbooks published in English-speaking countries, German-speaking countries, Chinese-speaking countries, and Japanese-speaking countries analyzed in the previous study [10-12]. The researcher analyzed two categories classified into traditional technology and new technology in the previous study [10-16]. In this study, the two categories were used to analyze in Figure 3.
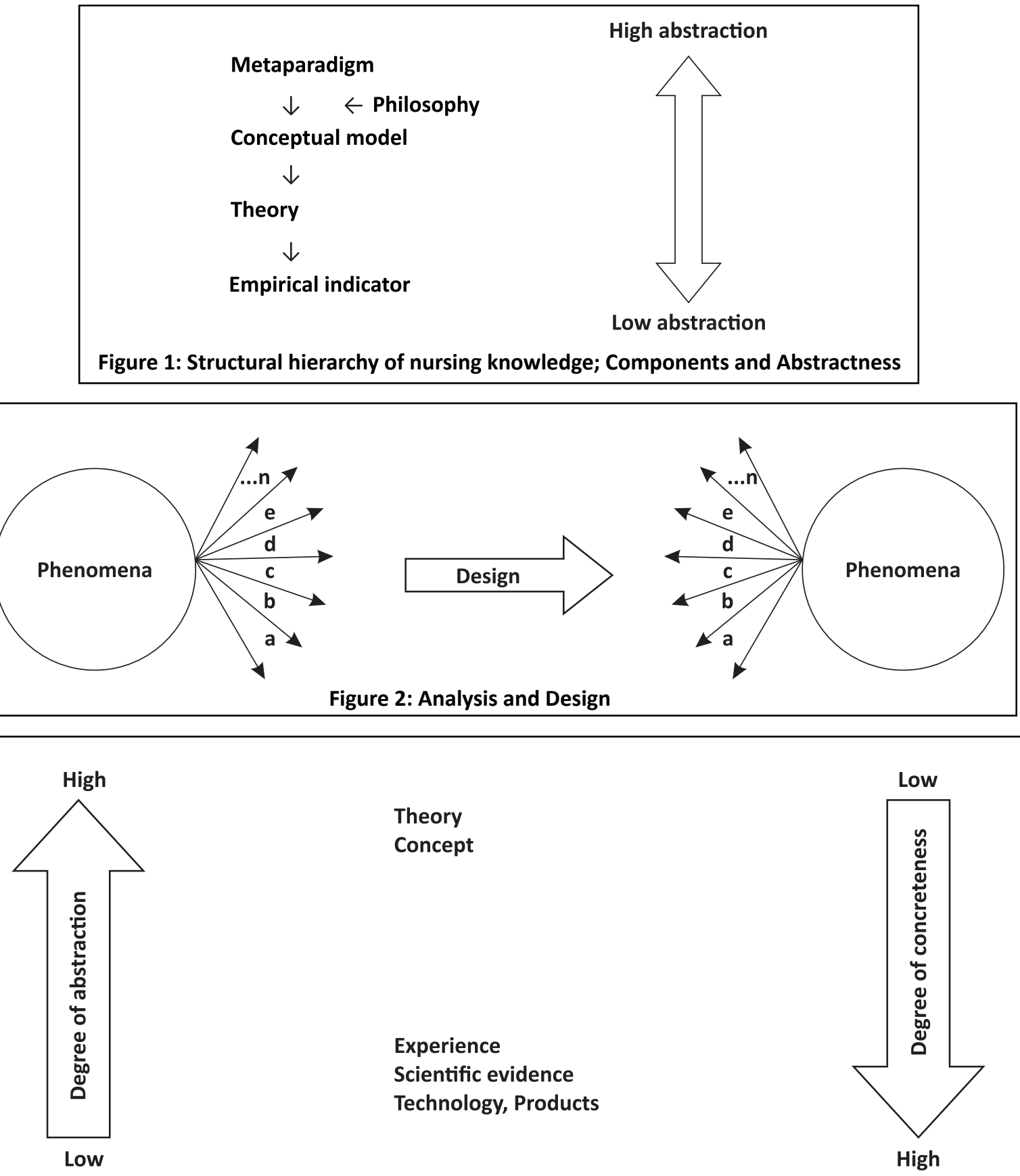

Figure 3: Theory and Concept; Embody and Creation

Citation: Hiroko Tadaura (2021). Difference between Metaphysics and Physical Applications; Comparison of Classical and New Patient Positioning. POJ NursPrac Res. 5(1):1-5. DOI: https://doi.org/10.32648/2577-9516/5/1/2. 


\section{RESULTS}

\section{Traditional Patient Positioning}

Comparison of Tradition and New Practice in Patient Positioning was shown in Figure 4. Traditions mainly focused on physical movement from one place to another. Its main objectives were physical movement itself and prevention of pressure ulcers. Based on the study of Human Engineering, techniques were devised, and physics was applied that could be efficiently supported by nurses with little effort. The tradition was based on the idea that nurses would perform the task of changing the patient's position instead of the patient who could not move, and that the nurse would perform the task of changing the position of the patient. The nurse's work-energy or Transfer

Devices were provided, and the patient was passive in changing position without producing this energy.

When force $\mathrm{F}$ acts on an object and its Patient Positioning's by $\Delta \mathrm{x}$, the work W (J) that force $\mathrm{F}$ does on the object is below. In the traditional Patient Positioning, the idea of creation for the working energy was by nurses' side, not Patients.

$W=F \cdot \Delta x$

$W=$ Nurses' side or Transfer Devices

There were patterns and methods of technology, and they were basically used in any patient.

\begin{tabular}{|c|c|c|c|c|c|}
\hline \multirow{14}{*}{ 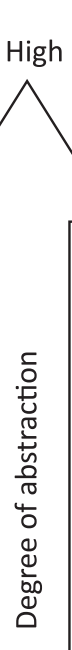 } & \multicolumn{2}{|l|}{ Tradition } & \multicolumn{3}{|c|}{ New } \\
\hline & Physical transfer & Nurses do the work & Ontogenesis & $\begin{array}{l}\text { Patients do the work } \\
\text { by themselves }\end{array}$ & \\
\hline & Prevention of pressure & instead & Exercise physiology & Patients' $W=F \cdot \Delta_{X}$ & \\
\hline & ulcers & Nurses' or Transfer & Human engineering & Nurses support the & 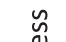 \\
\hline & Human Engineering & Devices' $W=F \cdot \Delta_{X}$ & Biomechanics & process & \\
\hline & & & $\begin{array}{l}\text { Neural science } \\
\text { Gravity Health Sciences }\end{array}$ & & \\
\hline & & & Rehabilitation & & రิ \\
\hline & & & Cybernetics & & 5 \\
\hline & & & Psychology & & $\frac{\omega}{20}$ \\
\hline & & & Bioethics & & एँ \\
\hline & & & Holistic care: Physical, & tal, and Social & \\
\hline & & & Learning theory, pedag & & \\
\hline & & & Communication Theor & & \\
\hline & & & Self-Care theory & & \\
\hline & & & Awareness theory & & \\
\hline & & & Comfort theory & & \\
\hline Low & & & Theor & & High \\
\hline & A pattern of skills & & Individual Creation wit & atients in presence & \\
\hline & Methods & & & & \\
\hline & Figure 4: Com & arison of Tradition & New Practice in Pati & Positioning & \\
\hline
\end{tabular}

\section{New Patient Positioning}

Based on embryology and human development, the new concept was aimed at helping people by respecting natural and primitive movements. Infant movements such as convulsions, gravity, and voluntary physical movements were applied to assist the patient. This is categorized in Nursing applied Ontogeny and Ontogenesis. Nursing care is defined as the promotion of health, prevention of illness, care for physical illness, mental illness, individual care, dignified care, planning, implementation and evaluation [17]. The new concept has the application of the definition of Nursing care in Patient Positioning. In the classification of kinesiology, there are two systems: The Animal system (muscles and nerves), and the Plant system (respiration, circulation, and metabolism).

It is divided into the following: The animal system is related to the performance, exercise control, and command. The plant system is a physiological response (body Resources), and it works with the maintenance of the exercise [18]. The concept was applied in the new Patient Positioning [19]. Human Engineering is also applied in the new concept. Biomechanics, Neural science, Gravity Health Sciences, Rehabilitation, Cybernetics, Psychology, Bioethics, Holistic care, learning theory, Pedagogy, Communication Theory, Self-Care theory, Awareness theory, Comfort Theory, and theory of Soul needs are also reported in the new concept $[11,12,20-30]$.

When force $\mathrm{F}$ acts on an object and its Patient Positioning's by $\Delta \mathrm{x}$, the work $\mathrm{W}(\mathrm{J})$ that force $\mathrm{F}$ does on the object is below. In the new Patient Positioning, the idea of creation for the working energy was by Patients' side not Nurses mainly.

$W=F \cdot \Delta x$

$W=$ Patients $^{\prime}$ side

The new Patient Positioning was a technique to create individual support with patients in presence.

\section{DISCUSSION}

The classical technique included fewer concepts than the 
new one. About 50-year nursing history study on Japanese nursing textbooks found that physical movement and bedsore prevention were consistently described in the textbooks on Patient Positioning from the postwar period to the present [31]. The study also points out that nursing concepts applied to nursing skills have developed more comprehensively over the past 50 years [31]. The new concept was a Nursing approach that comprehensively satisfying physical, mental, and social aspects to be realized in the process of Patient Positioning. It has become clear that the new concepts and techniques are not merely techniques but are not implemented for the sole purpose of preventing pressure ulcers, not just physical movement. In the new concept of the Patient Positioning, it was nursing itself. In kendo (Japanese art of fencing) and Sado (Japanese tea ceremony), it indicates the stage of training [32]. "Syu" is the stage in which a person faithfully adheres to the teachings, forms, and techniques of the master or school and steadily acquires them. "Ha" is the stage to think about the teachings of other masters and schools, to adopt good ones, and to develop things. "Ri" is the process of leaving a school and creating and establishing a new and unique style [32]. The new concept and the application of the technics seem to be the "Ha" or "Ri" level. This is also a level of "Art" to create in the present. It also embodies patientcentered care and individualized patient support.

Movements relate to everything in our daily lives: Eat, defecate, keep clean, sit, sleep, stand, move, talk, look, listen, laugh, throw trash, Writing, etc. Movement is a daily life itself, and movement is life itself. Human beings are motor dependent organisms, and inactivity leads to death [33]. It can be said that who creates the movement is directly linked to life. In the classic concept, the patient is not a motion-producing protagonist but a heavy mass of the passive body physically moved by someone. The new concept is that the patient moves on his/her own as the protagonist of the moving energy, and the nurse supports the process of the moving. Classical and new concepts differ greatly in who creates work energy. It's also reported that the new concept lets you feel as if you're moving [20-27]. Studies of nurses and the elderly have also shown that nurses can achieve professional satisfaction and contribute to improved quality of life for the elderly [11]. Nurses and the elderly have a better sense of motion than classical techniques, and it has been found that the elderly have lower muscle tone [11]. It has also been proven that backache lowering and analgesic internal use of the nurse who uses the new concept are low [11]. In addition to studies on the transition of concepts and technologies, studies on effects and evidence are also needed.

\section{CONCLUSION}

Traditional Patient Positioning had two concepts: physical transfer and prevention of pressure ulcers. The new ones are individual and comprehensive creations with different holistic concepts. The technology was created together with the patient in presence. The working energy $(J)$ of patient positioning has been traditionally provided by nurses or Transfer Devices, not patients. Still, in the new application, patients themselves performed, and the nurses were the supporters of the moving process.

\section{COMPETING INTERESTS}

Author declares no competing interests.

\section{FUNDING}

This work was supported by JSPS KAKENHI Grant Numbers JP17H01692.

\section{References}

1. Lorraine Olszewski Walker. A method of theory building in nursing. Igakusyoin, Tokyo, 2008. (Japanese)

2. Yamagiwa Y. Disassembly design engineering. The University of Tokyo Press, Tokyo, 2013.

3. Donaldson S.K. \& Crowley D.M. The discipline of nursing. Nurs Outlook. 1978;26(2):113-120.

4. Dictionary Cambridge. Available from: https://dictionary.cambridge.org/ja/dictionary/english/concept. Accessed on: 21/Nov/2020.

5. Chinn, Peggy, Kramer, Maeona (November 30, 2010). Integrated Theory \& Knowledge Development in Nursing (8 ed.). St. Louis: Mosby. ISBN 978-0-32307718-7.

6. "Explanation". Available at: http://intranet.tdmu.edu. te.ua/data/kafedra/internal/magistr/lectures_stud/ English/First\%20year/Nursing\%20diagnosis/2.\%20 Nursing\%20theory\%20-\%20history\%20and\%20modernity.htm. Accessed on: 21/Nov/2020.

7. Dictionary Cambridge. Available from: https://dictionary.cambridge.org/ja/dictionary/english/empirical. Accessed on: 21/Nov/2020.

8. Online Etymology Dictionary. Available from: https:// www.etymonline.com/search?q=design. Accessed on: $21 /$ Nov/2020.

9. Eijiro dictironary. Available from: https://eowp.alc. co.jp/. Accessed on: 21/Nov/2020.

10. Tadaura H, Kunii K. Comparison of German, Japanese, and Chinese Basic Nursing Textbooks in Helping with Patient Positioning and Mobile Transfer. The 27th Academic Meeting of Japan Society for Rehabilitation Nursing, The Westa kawagoe, Saitama, Japan, November, 2015. (Japanese)

11. Tadaura H. New innovation of Nursing movement care. Nursing World Conference, Dubai, 27-29 October, 2016.

12. Tadaura H. Nursing Relativity -Prevention and Management of Pressure Ulcers. International Conference on Wound Care, Tissue Repair and Regenerative Medicine, London, UK, June 14-15, 2018. 
13. Arita $K$, Ishida $H$, Imai $H$, et al. Systematic Nursing Course Series: Basic Nursing Technology I, Igakushoin, Tokyo, (16), 2015. (Japanese)

14. Zhou Kexiong. 21st century High School of Medicine teaching materials, Basic Nursing Skills, China, 2014. (Chinese)

15. Potter PA, Griffin AP, Stockert $P$, et al. Fundamentals of Nursing. 9th ed. Elsevier Inc; 2016.

16. Lektorat Pflege, Nicole Menche. Pflege Heute. 4th ed. München : Elsevier Urban \& Fischer; 2007. (German)

17. International Council of Nurses. Available from: https://www.icn.ch/nursing-policy/nursing-definitions.

18. Maruyama H. Basic knowledge of exercise physiology and specific research methods. Japanese Physical Therapy Association. 1991;18(3):349-353.

19. Eisenschink A. Auswirkungen der kinaesthetischen Monbilisation im Vergleich zur Standardmobilisation auf die Atemfunktion bei Patienten nach aorto-coronarer Bypass-OPeration. Pflege. 2003;16:205-215. (German)

20. Tadaura $H$, Tokunaga K. From Body mechanics to Kinaesthetik/Kinaesthetics. The Japanese Journal of Nursing Science. 2006;31(10):49-53. (Japanese)

21. Tadaura H. Guide of new movement Care, From Body mechanics to Kinaesthtics. VIVO. 2016;8:30-34. (Japanese)

22. Tadaura H. Movement support to prevent Pressure Ulcer using Kinaesthetik/Kinaesthetics: Actual care using Kinaesthetik/Kinaesthetics. The Japanese Journal of Nursing Science. 2016;31(3):15-39. (Japanese)

23. Tadaura H, Tokunaga K. Nursing Application of Kinaesthetik/Kinaesthetics concept; Usefulness and evidence of Kinaesthetik/Kinaesthetics. EBNursing. 2005;5(4):534-539. (Japanese)
24. Tadaura H. Chapter of Kinaesthetics, Supervision Dai et al: The Theory of Home Nursing (2): Technology to Support, Home Care. Nursing Graphicus, Tokyo, Japan. 2018. (Japanese)

25. Tadaura $\mathrm{H}$, Tokunaga K. Chapter 2 - Positioning and its historical consideration, Editorial supervision: Makiko T, Positioning - Basic and practice of Position management. Nakayama Shoten Co Ltd. 2013;37-44. (Japanese)

26. Tadaura H. Chapter 4 Care and evidence for Cancer patients, 2. Investigation of Comfort and Evidence from patients: Positioning, Editorial supervision: Asano M, Cancer Nursing, Nankodo. 2012;17(2):281284. (Japanese)

27. Tadaura H, Kumiko Sakaki. Score of SOPMAS in the Kinaesthetics and Body Mechanics Groups, The 18th Annual Congress of Japanese Society of Pressure UIcer, Yokohama, Japan, 2016. (Japanese)

28. Hatch F, Maietta L, Schmidt S. Kinästhetik: Interaktion durch Berührung und Bewegung in der Pflege. 1st ed, DBfK, Frankfurt, 1996.(German)

29. Bauder HM. Kinästhetik in der IntensivPflege: Frühmobilisation von schwerstkranken Menschen. 1st ed, Schlütersche, Hannover-Germany, 2000. (German)

30. Asmussen M. Praxisbuch Kinaesthetics, Erfahrungen zur individuellen Bewegungsunterstutzung auf Basis der Kinaesthetik, 2nd ed, Urban \& Fischer Bei Elsev, Munchen-Germany, 2006. (German)

31. Mashima T. Historical changes in the description of pressure injury in nursing textbooks, Master's thesis at International University of Health and The Welfare, 1-57, March 2020. (Japanese)

32. Hujihawa R. Shubariri-no-shiso, Baseball Magazine, Tokyo, 1993.

33. Atomi Y. Increase "cellular force"; extend healthy life expectancy from "mind-body science", Ronsosya, Tokyo, 2018. 